\title{
A Necessária Regulamentação Da Telemedicina No Brasil Na Perspectiva Do Desenvolvimento: A Crise Covid-19 Como Parâmetro A Ser Observado
}

\author{
Jefferson Patrik Germinari* \\ Universidade de Marília, Programa de Pós-Graduação em Direito, Marília-SP, Brasil. \\ (iD) http://orcid.org/0000-0002-3741-5651 \\ Marisa Rossignoli** \\ Universidade de Marília, Programa de Pós-Graduação em Direito, Marília-SP, Brasil. \\ (iD) http://orcid.org/oooo-0001-6223-9146 \\ Bruno Bastos de Oliveira*** \\ Universidade de Marília, Programa de Pós-Graduação em Direito, Marília-SP, Brasil.
}

Resumo: A pandemia provocada pela COVID-19 retomou as discussões em torno da telemedicina, cujas modalidades anteriormente não regulamentadas passaram a ser provisoriamente autorizadas para o enfrentamento da crise. O presente artigo tem como objetivo analisar tal cenário sob as prerrogativas constitucionais, com enfoque sobre o direito à saúde e à atuação do Estado no desenvolvimento humano e econômico. Adotou-se metodologia de pesquisa dedutiva, partindo da ideia geral circulante nas normas constitucionais inclinadas aos direitos sociais e econômicos. Conclui-se, considerando a crise pandêmica da COVID-19 um momento ruptivo, que a regulamentação definitiva da telemedicina no Brasil pode proporcionar ambiente favorável à implementação de valores sociais e econômicos, dando maior efetividade de tutelas fundamentais do ser humano, assumindo assim papel de gatilho para ampliação do desenvolvimento humano e econômico.

Palavras-chave: Regulamentação. Telemedicina. COVID-19. Desenvolvimento.

10.22478/ufpb.1678-2593.2020v19n42.53009

* Mestrando em Direito na Universidade de Marília - Unimar. E-mail: jgerminari@tjsp.jus.br

*** Doutora em Educação. Professora Permanente do Programa de Pós-Graduação em Direito da UNIMAR. E-mail: mrossinholi@uol.com.br

*** Doutor em Ciências Jurídicas. Professor Permanente do Programa de Pós-Graduação em Direito da UNIMAR. E-mail: bbastos.adv@gmail.com

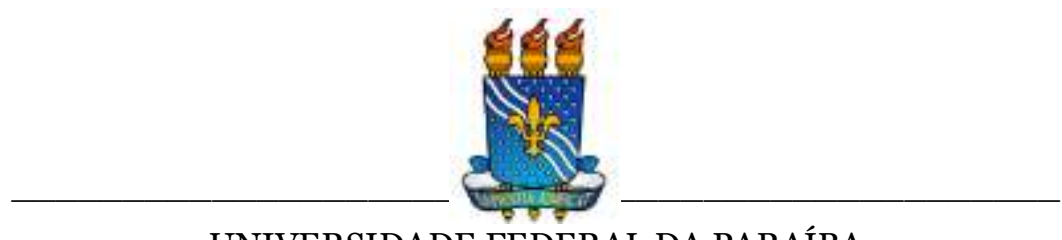

UNIVERSIDADE FEDERAL DA PARAÍBA

Programa de Pós-Graduação em Ciências Jurídicas

DOI: https://doi.org/10.22478/ufpb.1678-2593.2020v19n42.53009 


\title{
A Necessária Regulamentação Da Telemedicina No Brasil Na Perspectiva Do Desenvolvimento: A Crise Covid-19 Como Parâmetro A Ser Observado
}

\author{
Jefferson Patrik Germinari
}

Marisa Rossignoli

Bruno Bastos de Oliveira

\section{INTRODUÇÃO}

A partir da crise pandêmica, analisar-se-á a estreita relação que a Ordem Econômica e a Ordem Social guardam entre si, considerandose a telemedicina como alternativa de redução de desigualdades e desenvolvimento humano.

A medicina registrou inúmeros avanços ao longo de sua história; todavia, subestimar o fator surpresa e acreditar que se chegou a patamares insuperáveis nos mais distintos campos implica em oportunizar desarranjos sistêmicos. Exemplo disso é a crise vivenciada pela COVID-19 (coronavírus), desvelada em consequências de ordem normativa, econômica, política e social.

Tais ponderações justificam a necessidade de a telemedicina ser discutida com maior profundidade no Brasil na perspectiva do desenvolvimento e uma das razões condiz com o fato do país possuir desequilíbrios na distribuição da renda e disparidades na demografia médica, desabastecendo-se áreas mais pobres.

Esses e outros fatores que comporão o presente estudo apontam a necessidade de a telemedicina ser implementada no Brasil definitivamente, regulamentando novas modalidades de serviços médicos a serem praticados através de recursos tecnológicos de 
operação remota, enaltecendo o direito à saúde como primordial, potencializando-se reflexamente benefícios sociais e econômicos.

Diante da ideia de que direitos sociais e econômicos contemplam reciprocamente a realização do bem-estar, o objetivo deste artigo é, restringindo o estudo ao direito à saúde, analisar de que maneira a telemedicina pode funcionar como mecanismo de motivação nas duas searas, estimulando em conjunto o desenvolvimento humano e o econômico. Consubstanciando outros objetivos secundários que confluem ao principal, pretende-se analisar a telemedicina como mecanismo auxiliar para redução de desigualdades demográficas, verificando ainda a viabilidade de implantação sob a ótica do custobenefício e o valor econômico ao mercado empreendedor a partir do contexto da COVID-19.

Tais dinâmicas implicam na utilização do método de pesquisa dedutivo, em linearidade para cada seção de contexto teórico oportunizado com a utilização de recursos doutrinários e científicos, realizando-se em seguida amarras de contextualização do plano empírico e de dados.

\section{CONSTITUIÇÃO E DIREITO À SAÚDE: A TELEMEDICINA A SERVIÇO DO DESENVOLVIMENTO ECONÔMICO E SOCIAL}

As respostas normativas, na maioria das vezes, representam medidas de incentivos ou limitações daquilo que se extrai das transformações sociais precedentes; nesse sentido, merece destaque a Constituição Federal de 1988 que possui peculiaridades que a sustenta em patamar de importância significativamente superior quando comparada às demais Cartas Políticas norteadoras da sociedade brasileira, além de se afirmar como aprimoramento institucional do Estado, em termos de arranjos políticos, representa a concussão 
formal de conquista de direitos sociais que encabeçaram longa trajetória de lutas passadas.

Em linhas de baliza, a inspiração do Welfare State, envolvendo mínimas garantias de Bem-Estar; Esping-Andersen (1991, p. 98) questiona ainda se esta definição não deveria ultrapassar uma mera análise condizente a "saber se as políticas sociais são emancipadoras ou não; se ajudam a legitimação do sistema ou não; se contradizem ou ajudam no mercado, e o que realmente 'básico'?”, indagando, ainda, se não seria mais apropriado determinar a um welfare state realizações que ultrapassem as necessidades básicas do homem.

Saliente-se, ainda, as lições de Briggs (2006, p. 16) no sentido do Welfare State funcionar como parâmetro a ser observado para a regulação de forças de mercado em três direções, a primeira delas para garantir uma renda mínima não somente aos indivíduos, mas também às suas famílias, "independentemente do valor de mercado de seu trabalho ou de sua propriedade"; a segunda direção colocando os indivíduos e famílias "em condições de fazer frente a certas 'contingências sociais' (por exemplo, a doença, a velhice e a desocupação) que, de outra forma, conduziriam a crises individuais ou familiares"; e a terceira frente para assegurar de modo indistinto a todos os cidadãos, independente do status ou classe assumida, a oferta dos mais altos padrões de uma gama reconhecida de serviços sociais.

Desses apontes, extraem-se as ideias do Welfare State constituir em seu cerne mais primitivo, o estado de felicidade, ou seja, a concretização de variadas necessidades sociais umbilicalmente ligadas à dignidade humana nas quais podem ser identificadas no caput do artigo $6^{0_{1}}$ da Constituição Federal e quando efetivadas constituem o verdadeiro exercício da cidadania.

Bem recordam Cecato e Oliveira (2016, p. 18-19) o suporte dado pelos direitos sociais ao desenvolvimento, inadmitindo-se exclusões

\footnotetext{
${ }^{1}$ Art. $6^{\circ}$ São direitos sociais a educação, a saúde, a alimentação, o trabalho, a moradia, o transporte, o lazer, a segurança, a previdência social, a proteção à maternidade e à infância, a assistência aos desamparados, na forma desta Constituição.
} 
haja vista que a marginalização de determinada "camada da sociedade constitui obstáculo ao desenvolvimento, sendo igualmente verdade que o país dito desenvolvido não terá jamais parte de sua população à margem da subsistência material e completamente descartada da participação política, em lato sentido".

$\mathrm{O}$ direito à saúde se encontra intimamente ligado ao Estado do Bem-Estar e ganha maior importância em função da direta relação que possui com as demais garantias sociais, pois o seu termo compreende não apenas questões de acessibilidades aos serviços médicos e a programas de prevenção de doenças, alcança também a própria saúde psicológica, envolvendo série de satisfações básicas do homem como o acesso ao trabalho, boa educação, lazer, alimentação, propriedade, segurança; em conjunto, constituem gama de valores imprescindíveis à dignidade humana.

Nesse sentido, há de compreender a Carta Política como conjunto de normas sustentadas por "força jurígena e caráter vinculante significa aceitá-la como suporte basilar à proteção dos direitos fundamentais e às determinações de realização de políticas públicas voltadas para a efetivação dos direitos econômicos, sociais e culturais" (CARDOSO; FEITOSA, 2014, p. 3).

Frise-se, ainda, o direito à saúde encontrar-se sob o vértice dos Direitos e Garantias Fundamentais, o que significa afirmar estar sujeito à dinâmica do artigo $5^{\circ}, \S 1^{\circ}$ da Constituição Federal, "no sentido de que a todas as normas de direitos fundamentais há de se outorgar a máxima eficácia e efetividade possível, no âmbito de um processo em que se deve levar em conta a necessária otimização do conjunto de princípios (e direitos) fundamentais", sempre à luz do caso concreto (SARLET; FIGUEIREDO, 2008, p. 6).

Em se considerando a saúde produto advindo de complexas condições objetivas de vida, alcançando dimensões biológicas, sociais, e culturais, que se realiza não apenas em curso político, mas também das relações exercidas pelo próprio homem, "é através das relações sociais de produção que se erguem as formas concretas de vida social. 
E o estado de saúde corresponde a uma das revelações dessas formas de vida" (PAIM, 1986, p. 4).

O Estado Democrático brasileiro sustenta-se em dois importantes eixos, quais sejam, a Ordem Econômica, encabeçada no artigo 170, e a Ordem Social, a partir do artigo 193, trabalhando de modo correspondente a assegurar direitos com preeminência à liberdade, segurança, igualdade e justiça, todas inclinadas ao desenvolvimento econômico e social, reduzindo-se as desigualdades econômicas e de direitos cidadãos estampados na Carta Política.

Restringindo-se à seara da saúde, deve-se ponderá-la em duas dimensões distintas que atualmente pairam sobre o sistema vigente. A primeira delas é o olhar da saúde como um direito inserido em um sistema de proteção social, fator que cooperou à desmercantilização de seu acesso, corroborando-se ao preceito de universalidade e integralidade dos artigos 196 e 198 da Constituição Federal de $1988^{2}$. A segunda dimensão é a observação da saúde como um bem econômico propulsor do sistema de oferta de mercados, voltado ao acúmulo de riquezas e proventos profissionais, colaboradores à formação do ramo privado de prestadores de serviços médicos, exames e planos de saúde.

Em meio a essa correlação empírico-teórica, logo após a promulgação da Constituição de 1988, coincide o advento da era digital e com isso o surgimento da ideia em se disseminar os recursos de tecnologia da informação e comunicação ao serviço de saúde no Brasil. Assim, nasce a telemedicina como possibilidade de prestação médica através de recursos tecnológicos de operação remota, integrando objeto de estudos e experimentos tanto na esfera pública

\footnotetext{
${ }^{2}$ Art. 196. A saúde é direito de todos e dever do Estado, garantido mediante políticas sociais e econômicas que visem à redução do risco de doença e de outros agravos e ao acesso universal e igualitário às ações e serviços para sua promoção, proteção e recuperação.

Art. 198. As ações e serviços públicos de saúde integram uma rede regionalizada e hierarquizada e constituem um sistema único, organizado de acordo com as seguintes diretrizes: I - descentralização, com direção única em cada esfera de governo; II - atendimento integral, com prioridade para as atividades preventivas, sem prejuízo dos serviços assistenciais; III - participação da comunidade.
} 
quanto privada, apesar de em outros países já se denotar experimentos muito antes disso.

Deste modo, verifica-se o complexo de amarras econômicas e sociais, situando a telemedicina como objeto a ser analisado, a imersão sobre as possibilidades de estimular o desenvolvimento a partir da defesa do direito à saúde e a promoção do crescimento econômico, considerando as distintas dinâmicas mas que guardam íntima relação entre si, tanto o árduo trabalho do Estado a partir de implementação de políticas públicas de aprimoramento institucional e normativo, como a participação da iniciativa privada e por consequência a sociedade que constitui a força pujante de assimilar diferentes contextos e se transformar.

\subsection{Planos governamentais de incentivo e disseminação ao desenvolvimento da telemedicina no Brasil}

Antes do início do século XXI, raras ações políticas indiretas de incentivo à telemedicina foram apontadas; como exemplo, o Decreto $\mathrm{n}^{0}$ 100, de 16 de abril de 1991, que instituiu a Fundação Nacional de Saúde (FNS), daí surgindo o Departamento de Informática do Sistema Único de Saúde (DATASUS), tendo como função o processamento e controle das contas de saúde e a responsabilidade de prover os órgãos do SUS com sistemas de informações e informática.

Posteriormente, registra-se a publicação da Resolução $\mathrm{n}^{0} 53$, de 14 de setembro de 1998, criada pela Agência Nacional de Telecomunicações (ANATEL), instalando-se o Comitê sobre Infraestrutura Nacional de Informações; logo em seu primeiro artigo se vê estampado o elementar objetivo paradigmático do grupo, qual seja, formular proposições e recomendações relacionadas ao setor de telecomunicações que contribuam com o desenvolvimento e o uso da Infraestrutura Nacional de Informações, abarcando, dentre os 
diversos eixos de atuação, um grupo temático na área da saúde, com participação de algumas entidades de destaque, como a Fundação Oswaldo Cruz, a Rede Sarah, Ministério da Saúde, Telecárdio, Unicamp, Ministério do Exército, Associação Médica de Brasília e representação da União Internacional de Telecomunicações.

Em 17 de agosto de 2000, a Lei ${ }^{0} 9.998$ instituiu o Fundo de Universalização dos Serviços de Telecomunicações (FUST), com recursos provenientes de $1 \%$ da receita operacional bruta dos serviços de telecomunicações público e privado, entre outras dotações, destinando-se a integrar programas e projetos implementados consoante políticas, diretrizes e prioridades sob coordenação do Ministério das Comunicações.

Diante do movimento internacional que se fez presente na virada do século XX para o XXI, a citar, a $51^{\text {a }}$ Assembleia Geral da Associação Médica Mundial realizada em Israel, na qual se aprovou a Declaração de Tel Aviv que dispõe sobre responsabilidades e normas éticas na utilização da telemedicina; a Health On the Net Foundation (HON)3, apontou no ano de 2001, pesquisa dedicada a demonstrar a tendência de utilização de serviços médicos na internet; a Organização Pan-Americana de Saúde, em conjunto com a OMS, que apresentaram no mesmo ano o manual intitulado regulamento sobre privacidade e proteção de dados no uso da Informação Eletrônica. Não apenas esses fatores, como o ambiente interno de experiências institucionais públicas e privadas, elevaram a temática à importância de tomadas políticas.

Como sinalização, o Conselho Federal de Medicina aprovou a Resolução CFM no 1.643, de 7 de agosto de 2002, regulamentando as primeiras atividades remotas a serem praticadas sobre o seu Norte. Em 16 de março de 2006, por meio da Portaria ${ }^{0} 561$, o Ministério da Saúde instituiu a Comissão Permanente de Telessaúde, tendo, entre

3 Criada em 1995, uma organização não governamental baseada na Suíça, tendo por missão orientar médicos e usuários não praticantes quanto ao uso confiável de informações médicas on-line e demais informações de saúde. 
suas atribuições, o assessoramento de projetos em andamento de telessaúde sob sua jurisdição, o acompanhamento de sistemáticas para atualização profissional continuada remota, criação de base de informação estratégica sobre implementação de telemedicina e telessaúde, entre outros (BRASIL, 2006), portaria essa que foi revogada pela até então vigente Portaria $n^{0}$ 452/2010, a qual apresentou alterações no quadro de participantes do programa.

Entre os anos de 2008 e 2012 ocorreram alguns repasses financeiros do Ministério da Saúde para os núcleos do Projeto-piloto Telessaúde Brasil, a "maioria das universidades recebeu $\mathrm{R} \$ 2,3$ milhões; a UFRGS recebeu R \$,2 milhões. Houve, além desse aporte para a UFRGS, um financiamento para o projeto de pneumologia e telessaúde, o RespiraNet (R $\$ 284$ mil). A UFMG também recebeu mais financiamento (R\$ 2,7 milhões)" (SILVA; CARNEIRO; SINDICO, 2015, p. 173).

Merece destaque, também, a Portaria $\mathrm{n}^{0}$ 2.546/2011, que redefiniu e ampliou o Programa de Telessaúde Brasil, denominandose a partir daí Programa Nacional Telessaúde Brasil Redes, estabelecendo-se quatro espécies de serviços de telessaúde, quais sejam, teleconsultoria, telediagnóstico, tele-educação e segunda opinião; no ano seguinte, o advento da Portaria $n^{0}$ 1.229/2012, que estabeleceu recursos financeiros ao programa.

No ano de 2018, o Conselho Federal de Medicina aprovou a Resolução CFM n ${ }^{0}$ 2.227/2018, ampliando o conceito de telemedicina, permitindo e regulamentando novas modalidades de serviços médicos remotos até então bastante restritos no Brasil; surpreendentemente, revogada meses após sua aprovação pela Resolução CFM $\mathrm{n}^{\circ}$ $2.228 / 2019$, medida esta justificada no sentido de que a telemedicina fosse mais discutida por médicos e órgãos representativos, inclusive com chamada pública de sugestões para que novas deliberações fossem tomadas, das quais, até o presente momento, não foram definitivamente implementadas. A posteriori, o advento da Resolução $\mathrm{CFM} \mathrm{n}^{0}$ 2.264/2019 regulamentou a telepatologia como mecanismo a ser utilizado para fins de envio de dados e imagens com o propósito de 
emissão de relatório como suporte às atividades anatomopatológicas desenvolvidas localmente (BRASIL, 2019).

O ambiente de crise provocado pela pandemia da COVID-19 ensejou medidas rápidas e eficazes ao enfrentamento da crise. Como resposta, o advento da Lei 13.979, de 6 de fevereiro de 2020, determinou, em seu artigo $3^{\circ}$, diversas medidas emergenciais a serem adotadas; em complementação a tal dispositivo, o Conselho Federal de Medicina reconheceu, por meio do Ofício CFM no 1.756/2020 COJUR, datado de 19 de março de 2020, enviado ao Ministério da Saúde, a eticidade e o alcance provisório de novas práticas de telemedicina, a citar: teleorientação, telemonitoramento e teleinterconsulta4, até que se encerre o quadro pandêmico. Em desdobramento, no dia 23 de março de 2020, foi publicada, no Diário Oficial da União, a Portaria no $467 / 2020$, ocasião em que o Ministério da Saúde, no artigo $2^{\circ}$, em caráter excepcional, tornou mais abrangentes as práticas de telemedicina, alcançando-se o "atendimento pré-clínico, de suporte assistencial, de consulta, monitoramento e diagnóstico". Acrescente-se a aprovação da Lei ${ }^{0}$ 13.989, de 15 de abril de 2020, trazendo, na energia do artigo $3^{\circ}$, nova abertura ao trabalho remoto para além das disposições especificadas pelo Conselho Federal de Medicina, qual seja, a prática da telemedicina visando a prevenção de doenças, lesões e promoção de saúde.

É possível perceber, das políticas públicas e histórico regulamentar, que a telemedicina foi implementada com ressalvas no Brasil, cujos limites de sua extensão foram determinados ao que se considera a sua própria definição, com tentativa frustrada de aprimoramentos no ano de 2018 e incentivos de difusão provisória a partir do contexto da COVID-19.

\footnotetext{
4 "Teleorientação: para que profissionais da medicina realizem, a distância, a orientação e o encaminhamento de pacientes em isolamento; Telemonitoramento: ato realizado sob orientação e supervisão médica para monitoramento ou vigência, a distância, de parâmetros de saúde e/ou doença. Teleinterconsulta: exclusivamente para troca de informações e opiniões entre médicos, para auxílio diagnóstico ou terapêutico."
} 


\subsection{Telemedicina: algumas experiências públicas e privadas no Brasil}

A aplicação da informática no sistema de saúde brasileiro tem início na década de 1970, sendo implementada em alguns centros universitários, em especial no Hospital da Universidade Federal do Rio de Janeiro, no Instituto do Coração e nos Hospitais das Clínicas da USP-São Paulo/Ribeirão Preto. O professor da UFRJ, "Luiz Carlos Lobo, trouxe na época o MUMPS para o Brasil e fundou o Núcleo de Tecnologia de Educação em Saúde, que iniciou pioneiramente a aplicação de minicomputadores Digital PDP-11" com sistemas de apoio ao ensino (SABBATINI, 1998). Em 1971, o Hospital Albert Einstein também informatizou sua estrutura desenvolvendo sistema hospitalar de cadastro, internação, registro de diagnósticos e procedimentos em seus pacientes. Foi substituído em 1995 por novo software (MedTrak) para implantação de prática integrada com funções clínicas e administrativas hospitalares (KHOURI, 2003, p. 157).

Uma das primeiras práticas de telemedicina brasileira ocorreu em meados da década de 1980, no Núcleo de Informática Biomédica da Universidade Estadual de Campinas, em decorrência de acidente ocorrido em Goiânia por contaminação de césio radiativo, que foi liberado de equipamento biomédico abandonado (NADAI, 2018).

Utilizou-se de sistema baseado em computador de 8 bits (Itautec I-7000), interconectado pela Rede Nacional de Pacotes operada pela Embratel em hospitais de Brasília, Goiânia, Rio de Janeiro e Campinas para recebimento, via e-mail, de relatórios e aconselhamento médico (SABBATINI, 2012, p. 5).

No ano de 1985 a Faculdade de Medicina da Universidade de São Paulo integra a disciplina de informática médica, sendo que diante 
da inexistência de percepção da revolução digital e desinteresse do governo, as iniciativas até então tomadas foram sustentadas em projetos autônomos, descoordenados entre si, com o fito de atender distintos objetivos consoante as necessidades de cada ente. Somente a partir do ano 2000 que passa a haver maior empenho e preocupação relacionada a redes e salas de conferências, tele-educação na área de saúde, "teleconferências médicas com o exterior, em geral para pacientes da rede privada, a telecardiografia, por fax e depois pela internet em setores públicos e privados"; engajando-se como primeiros na difusão da telemedicina os Estados de Minas Gerais, Pernambuco, Santa Catarina e São Paulo (BÖHM, 2013).

Algumas atividades realizadas pelo setor empresarial merecem destaque, a grande maioria em meados da década de 1990, exemplo da empresa Telecardio para oferta de diagnóstico e monitoração remota cardiológica cujos clientes, em grande maioria, eram hospitais de pequeno porte, clínicas desprovidas de médicos especialistas, casas de repouso, clubes e academias. O Laboratório Fleury, a partir de 1996, disponibilizou página institucional na web para conexão com seus clientes, externalizando, no ano seguinte, acesso a resultados de exames por meio do sistema S-Line, possuindo, atualmente, mecanismos mais avançados, como agendamento de exame on-line, notificação por e-mail e disponibilidade de exames a pacientes por meio do seu site; oferece, também, aulas multimídia e publicações científicas (KHOURI, 2003, p. 162-165).

Também merece destaque o trabalho desenvolvido pelo InCor a partir de 1995, na área de telecardiologia, com a criação do ECG-FAX, para análise de eletrocardiogramas enviados de outras regiões para análise por parte dos profissionais atuantes no Instituto. Um ano após, foi lançado o serviço de ECG - Home, visando o telemonitoramento domiciliar de pacientes. Em 1998, a disciplina do Departamento de Patologia da Faculdade de Medicina da USP, com o próprio laboratório de investigação médica, criou a Rede Nacional de Informações em Saúde (RNIS); no mesmo ano, o Instituto de Radiologia do Hospital 
das Clínicas da FMUSP (InRad) delineou novo plano de informatização objetivando a integração com sistemas corporativos (KHOURI, 2003, p. 130 e 147).

Vislumbra-se maior expansão da telemedicina no início do século XX, a partir da publicação pelo Conselho Federal de Medicina da Resolução $\mathrm{n}^{0}$ 1.643/2002, com maior densidade a partir de 2006, quando o Ministério da Saúde instituiu "a Comissão Permanente de Telessaúde e, em janeiro de 2007, o Programa Nacional de Telessaúde com o protótipo aplicado na Atenção Primária, implantando redes assistenciais em nove estados" (RIBEIRO FILHO; MESSINA; SIMÕES; COURY, 2008, p. 98).

Uma das iniciativas públicas de grande importância nacional também merece destaque: a criação, no ano de 2006, da Rede Universitária de Telemedicina (RUTE), de iniciativa do Ministério da Ciência, Tecnologia e Inovação e sob coordenação da Rede Nacional de Educação e Pesquisa, com apoio da Financiadora de Estudos e Projetos (Finep), Associação Brasileira de Hospitais Universitários e da Empresa Brasileira de Serviços Hospitalares S/A. O trabalho inicial integrou 19 Hospitais Universitários (HUs); em 2007, já abrangia 38 instituições, "incluindo todos os HUs nas universidades federais e implantação de núcleos em Instituição Federal de Ensino Superior (IFES) ainda sem HUs; em 2008, mais de 26 instituições de saúde passam a fazer parte da rede". Tal projeto implantou a infraestrutura de comunicação nos hospitais universitários e de ensino nas maiores cidades do país e permitiu aplicações de Telemedicina, webconferência e tele-educação (SIMÕES; COURY; RIBEIRO; ARAÚJO; CAETANO, 2013, p. 11 e 14).

Certo é que, desde então, as práticas telemáticas ficaram restritas às modalidades deliberadas pelo Conselho Federal de Medicina não se notando alterações significativas do ponto de vista de novas aplicações, postergadas à expectativa de novas deliberações provisoriamente adquiridas em face da pandemia.

A COVID-19 provoca especulações tantas que anunciam ambiente complexo de instabilidades, ensejando reflexão acerca do 
A Necessária Regulamentação Da Telemedicina No Brasil Na Perspectiva Do...

momento presente e a possibilidade de nova ruptura, destacando a telemedicina como parâmetro de desenvolvimento dado o seu valor econômico e os benefícios sociais alcançados, os quais serão demonstrados nas próximas seções.

\section{RUPTURAS DE PARADIGMAS NO ÂMBITO DA IMPLEMENTAÇÃO DO DESENVOLVIMENTO NACIONAL: CONTORNOS TEÓRICOS A PARTIR DO CONTEXTO DA COVID-19}

Há de considerar o austero clima econômico que se anuncia resultante do quadro provocado pela COVID-19, importando reflexão no que toca a dependência que o desenvolvimento econômico guarda com diversas áreas, outrora teorizado por Joseph Alois Schumpeter, em sua obra Teoria do Desenvolvimento Econômico, ao estabelecer a diferenciação que há de ser observada entre o desenvolvimento social e o econômico.

Para o autor, o conceito de desenvolvimento social abrange, entre outras circunstâncias, o fato da mudança histórica "pela qual as condições sociais se tornam 'indivíduos' históricos no tempo", não constitui processo circular ou pendular sobre um cerne, o que atrela o fato de que "sempre que não conseguirmos explicar adequadamente um dado estado de coisas histórico a partir do precedente, reconhecemos, de fato, a existência de um problema não resolvido, mas não insolúvel”, exemplificando as alterações da política interna da Alemanha em 1919, um dos efeitos da guerra precedente. No tocante ao desenvolvimento econômico, afirma a dificuldade de guardar ligação exclusivamente a precedente econômico, pois estado econômico do povo não emerge tão somente das suas condições 
econômicas, mas do total de precedentes; considera o mundo econômico relativamente autônomo, uma vez que o setor econômico "está aberto a uma variedade sem fim de pontos de vista e tratamentos, que se podem ordenar, por exemplo, de acordo com a amplitude de seu alcance" (SCHUMPETER, 1997, p. 70-71).

Entende Schumpeter (1997, p. 74) que somente é possível afirmar a concepção de desenvolvimento quando mudanças na vida econômica não forem provocadas por circunstâncias de fora, mas que se restrinjam à própria iniciativa econômica; pretendendo-se afirmar que a economia variavelmente é modificada em face das mudanças que ocorrem no mundo à sua volta. Assim, "as causas e portanto a explicação do desenvolvimento devem ser procuradas fora do grupo de fatos que são descritos pela teoria econômica" (SCHUMPETER, 1997, p. 74), asseverando que todo processo concreto de desenvolvimento repousa, finalmente, sobre o desenvolvimento precedente.

A pertinência desse pensamento diante da atual circunstância decorre do peculiar olhar sobre rupturas cíclicas de desequilíbrios pelos quais se permeia o desenvolvimento, através de mudanças espontâneas e descontínuas no fluxo circular e perturbações sob o centro de equilíbrio perseguido, o que faz tracejar aberturas possíveis de desenvolvimento pós-crise provocada pela COVID-19, apresentando-se a telemedicina como alternativa aos avanços a serem alcançados na seara da saúde.

A comunicação teórica ao objeto de estudo se faz em função da telemedicina envolver a introdução de um novo bem, dos qual os consumidores não têm familiaridade alguma, a introdução de novo método de produção ainda não testado, podendo consistir em nova maneira de manejo de dada mercadoria; a abertura de novo mercado no qual a indústria de transformação não tenha atuado; a conquista de nova fonte de oferta de matérias-primas ou bens manufaturados e o estabelecimento de nova organização industrial, como a criação da posição de monopólio ou fragmentação (SCHUMPETER, 1997, p. 76).

Quanto aos ciclos os "movimentos contrários não apenas entravam o desenvolvimento, mas põem-lhe um fim. Uma grande 
quantidade de valores é aniquilada; as condições e os pressupostos fundamentais dos planos dos dirigentes do sistema econômico se alteram"; com o fito de reanimar o sistema econômico, novos valores são organizados com o tempo, e outra fase de desenvolvimento se inicia, inspirada em novas frentes, diferentemente das causas que promoviam as antigas transformações. "O novo desenvolvimento provém de condições diferentes e, em parte, da ação de pessoas diferentes; muitas esperanças e valores antigos são enterrados para sempre e surgem outros completamente novos" (SCHUMPETER, 1997, p. 205).

Relembrando as rupturas paradigmáticas, Mello (2017, p. 505) ressalta que a saúde pública mundial passou por três grandes momentos como a fase do saneamento empírico entre 1840 e 1890; na sequência, a era bacteriológica no controle de doenças infectocontagiosas que perdurou até o início do século XX e o período moderno fundado na educação sanitária e nos centros de saúde distritais. Quando se olha para dentro, verifica-se que a realidade brasileira "se revela no antes e depois da ruptura bacteriológica francesa com a atuação de Emílio Ribas e Oswaldo Cruz no começo do século XX".

Nesse breve retrospecto, considerando-se a COVID-19 e as peculiaridades brasileiras que serão abordadas na próxima seção, insta questionar se o momento atual não caracteriza novo quadro disruptivo com vista ao desenvolvimento, aproveitando-se os recursos tecnológicos disponíveis e a era digital, aqui a telemedicina considerada, como fator de desenvolvimento econômico e social; eis o desafio a que se dedica a próxima seção.

\section{A REDUÇÃO DAS DESIGUALDADES ECONÔMICAS E SOCIAIS A PARTIR DA REGULAMENTAÇÃO DEFINITIVA}




\section{DA TELEMEDICINA: CONSIDERAÇÕES TEÓRICAS E EMPÍRICAS}

Certo é que a telemedicina compõe locupletamento do rol de abordagens jurídicas, seja sob o ponto de vista do Direito Internacional, Tributário, Civil, Penal e Processual quando consideradas as modalidades recém autorizadas de prestação de serviços médicos, compondo inúmeras tessituras a serem pesquisadas pela classe científica. Janelas à parte, é inquestionável afirmar que a telemedicina, regulamentada no Brasil por conta da pandemia causada pela COVID-19, volta seu olhar ao direito gravitacional sobre a dignidade da pessoa humana, com a prevalência sobre o direito à vida mediante a facilitação do acesso à saúde, razão do corte metodológico de abordagem constitucional, em especial sobre os direitos fundamentais e o desenvolvimento.

Tais práticas, mesmo que excepcionais, fortalecem como elementar a ideia de implementação definitiva da telemedicina; concorrentemente, atribui ao Estado providências políticas estruturais, apresentando-se como alternativa plausível ao enfrentamento de obstáculos ocasionados no ambiente fragilizado pela pandemia; medida não somente ao desenvolvimento humano, na mira do cidadão como detentor de direitos fundamentais, mas sinônimo de avanço institucional do Estado, de aprimoramentos de serviços e, por consequência, novo gatilho disruptivo rumo ao desenvolvimento; também econômico, a partir de novas espécies a serem praticadas pelo sistema público e privado de saúde e que certamente influenciarão novos ares mercadológicos, em especial os que se dedicam à seara da tecnologia de informação e comunicação.

4.1 Renda, saúde e tecnologia: influências recíprocas de desenvolvimento econômico e social 
Importa mencionar que basicamente toda e qualquer definição de pobreza pode ser incluída em uma das três dimensões dispostas por Hagenaars e Vos (1987, p. 212), quais sejam, "A. Poverty is having less than an objectively defined, absolute minimum. B. Poverty is having less than others in society. C. Poverty is feeling you do not have enough to get along." 5 . Extraem-se daí algumas especificidades, a exemplo de pobreza absoluta, a insuficiência de renda para atendimento de necessidades básicas, as condizentes a custos fixos, percorrendo-se em linhas de pobreza relativa a privação de certo conjunto de bens que sejam comumente considerados em dado ambiente social. Afirmam Kageyama e Hoffmann (2006, p. 84) que:

[...] a pobreza tem uma dupla natureza: de um lado, devese ao subdesenvolvimento regional e local, que impõe privações em condições básicas de existência, como luz elétrica, água encanada e instalações sanitárias, e dificuldade de acesso aos serviços de saúde e educação; de outro lado, a pobreza tem raízes nas características demográficas e nas limitações do capital humano e financeiro das famílias, que prejudicam a capacidade de elevar a renda familiar. A superação do primeiro aspecto depende mais de investimentos públicos e privados em infra-estrutura e serviços básicos; o segundo aspecto teria que ser atacado em duas frentes: na melhoria da educação fundamental, incluindo programas de esclarecimento de controle da natalidade e de normas de higiene, e na melhoria das condições de acesso ao mercado de trabalho, seja pelo crescimento dos empregos assalariados, seja pelo apoio às atividades autônomas, ou pela diversificação das fontes de renda da família.

No entanto a análise transversal do desenvolvimento humano deve ser considerada, sendo "necessário cruzar informações relativas às estruturas jurídicas, políticas e econômicas, como indicadores capazes de aferir riqueza, sua distribuição e aplicação dos recursos

5 A. A pobreza é ter menos do que um mínimo absoluto e objetivamente definido. B. Pobreza é ter menos do que outros na sociedade. C. Pobreza é sentir que você não tem o suficiente para prosseguir adiante. (tradução nossa) 
públicos, e a pobreza, sua concentração e demandas, não desprezando jamais os resultados" (FEITOSA; SILVA, 2012, p. 140).

Analisar a relação existente entre renda e saúde se impõe haja vista que ambas terminologias são fatores de forte impacto no desenvolvimento econômico e social, Santos et al (2012, p. 229-330) alerta acerca da importância da renda e da saúde como agentes interlocutores do Bem-Estar, esclarecendo a existência de hipóteses de identificação sendo a primeira de que a renda afeta a saúde tendo em vista que permite gozar de melhor status como "aquisição de bens e serviços de saúde, acesso aos serviços de saúde, condições de moradia e educação" e a segunda consideração no sentido de que a saúde também afeta a renda, no sentido de que "o capital humano é um insumo associado com a capacidade da força de trabalho, a saúde impacta diretamente sobre a produtividade e oferta de trabalho afetando o crescimento econômico".

Analisando-se dados do Instituto Brasileiro de Geografia e Estatística de 2019, verifica-se que renda média familiar entre os Estados da Federação, incluído o Distrito Federal, perfaz o valor de R \$ 1.233,00, despontando a capital brasileira com renda de $\mathrm{R} \$ 2.686,00$, seguida pelos Estados da Região Sul e Sudeste com maiores índices, aqui considerados São Paulo ( $\mathrm{R} \$ 1.946,00)$, Rio de Janeiro ( $\mathrm{R} \$ 1.882,00)$, Rio Grande do Sul ( $\mathrm{R} \$ 1.843,00)$, Santa Catarina ( $R \$ 1.769,00)$ e Paraná ( $R \$ 1.621,00)$, assumindo a ponta oposta os Estados situados na Região Norte e Nordeste, com destaque para Maranhão (R \$ 636,00), Pará (R \$ 807,00), Alagoas (R \$ 731,00) e Piaú (R $\$ 827,00)^{6}$ (IBGE, 2019).

Pode-se afirmar que renda e saúde não apenas se correspondem mas caminham atreladas, basta comparar o fator Longevidade do Índice de Desenvolvimento Humano Regional (IDHM-L) dos Estados acima mencionados; considerando o valor 1 (um) como o mais alto padrão, dados relativos ao ano de 2017 mostram que entre os Estados

612 Estados possuem renda familiar abaixo do salário mínimo vigente de $\mathrm{R} \$$ $1.045,00$ 
que possuem melhor renda familiar ostentam melhores marcas: Distrito Federal $(0,890)$, São Paulo $(0,826)$ e Santa Catarina $(0,866)$ e entre os de menor renda estão os piores índices $(0,764)$, Pará $(0,788)$, Piauí (o,771) e Alagoas (o,783). (PND, 2019)

A fim de agregar reflexão às correlações entre renda e saúde, a tecnologia exsurge como amarras dessa dinâmica em prol do desenvolvimento; exemplo disso pode ser confrontado à experiência Chinesa que em meados da década de 1990 possuía PIB semelhante ao Brasil e no decorrer dos últimos 25 anos sextuplicou montantes em face da economia nacional, resultado de políticas explícitas de Ciência, Tecnologia e Inovação. Nesse sentido, Cassiolato (2013, p. 68) informa a realização de cinco grandes conferências chinesas ao longo dos anos (1978, 1985, 1995, 1999 e 2006) com o objetivo de discutir o papel da Ciência e Tecnologia (C\&T) no país e rumos a serem tomados. "As conferências foram idealizadas por Deng Xiaoping, que, na primeira delas, em 1978, pronunciou um famoso discurso afirmando que C\&T eram forças produtivas e que intelectuais faziam parte da classe trabalhadora”, elevando C\&T ao status de propulsor da modernização.

Destaca-se na trajetória chinesa o período compreendido entre os anos de 1995 e 2005, fase em que houve centralidade da Ciência, Tecnologia e Inovação no processo de desenvolvimento da China, com o "fortalecimento do sistema nacional de inovação e a aceleração da industrialização dos resultados dos avanços científicos e tecnológicos tornaram-se a diretriz política principal deste período”. Além disso foram criadas novas leis para geração de ambiente propício à negociação, inclusive apoiando empresas privadas, integrando o plano estratégico de desenvolvimento (CASSIOLATO, 2013, p. 72). O processo chinês de inovação resultou não apenas em crescimento econômico, mas refletiu em seu Índice de Desenvolvimento Humano, que saltou significativamente de 0,502 em 1990 para 0,752 em 2017 (COUNTRYECONOMY, 2018).

Deste modo, há que considerar a estreita comunicação que há entre renda, saúde e tecnologia que, alinhadas à política de incentivos 
de implementação, tem o condão de atuar como influenciadores de índices de desenvolvimento social e crescimento econômico.

Nesse sentido, diante do contexto atual, há de ser considerada a telemedicina também por sua viabilidade de agregar resultados no desenvolvimento, haja vista que tal instrumento tem o condão de atuar justamente sob o tripé abordado, considerada nova tecnologia no mercado brasileiro, fator de aprimoramento da saúde e dotação econômica.

A crise da COVID-19 criou grandes expectativas no mercado telemático fazendo que estimativas saltassem dos $\$ 45$ bilhões movimentados no ano de 2019 para $\$ 175,5$ bilhões em 2026, vez que "various telemedicine companies are witnessing a spike in virtual visits amid the COVID-19 pandemic. These companies are increasing their capability to handle several thousand virtual visits a day to meet the growing need, thus propelling the market growth."7. (UGALMUGLE; SWAIN, 2020)

Ocorre que a telemedicina não deve apenas funcionar como medida de valor econômico agregado. Há de ser assimilada como alternativa do sistema de saúde pública, por isso que a próxima seção está incumbida de demonstrar a viabilidade de implementação sob o aspecto do custo-benefício.

\subsection{Algumas constatações no plano empírico de custo- benefício}

Pela incipiência do tema, poucas pesquisas demonstram a viabilidade econômica de implementação de projetos. Um deles se

\footnotetext{
7 Várias empresas de telemedicina estão testemunhando um pico em visitas virtuais em meio à pandemia da COVID-19. Estas empresas estão aumentando sua capacidade de lidar com milhares de visitas virtuais por dia para atender a crescente necessidade, impulsionando assim o crescimento do mercado.
} 
refere ao Projeto Minas Telecardio (MTC), realizado entre os meses de junho de 2006 e novembro de 2008, consistiu na análise de eletrocardiogramas (ECG) enviados por 82 municípios espalhados pelo interior do Estado de Minas Gerais a especialistas que trabalharam em ritmo de plantões para avaliação dos exames e discussões online dos casos clínicos. O custo do projeto envolveu implantação ( $\mathrm{R}$ \$ 508.037,75), manutenção (R \$ 1.310.245,08) e avaliação (R\$ 315.658,31), sendo realizados no período 64 mil ECG, perfazendo o valor unitário de $\mathrm{R} \$ 28,92$. Para averiguação do custobenefício foram considerados os valores constantes da tabela SUS de 2008 que indicava o valor do exame de $\mathrm{R} \$ 5,15$ e consulta médica $\mathrm{R} \$$ 10,00. Ao agregarem eventuais despesas de deslocamento com o município mais próximo do polo de realização, constataram o valor a ser praticado de $\mathrm{R} \$ 30,91$, sendo que em caso de transporte e alimentação o valor unitário se elevava para $\mathrm{R} \$$ 49,83 (ANDRADE; MAIA; CARDOSO; ALKMIM; RIBEIRO, 2011, 308-312).

Outro trabalho que merece destaque foi a avaliação econômica do serviço de telemedicina prestado de setembro de 2017 a setembro de 2018 pelo Núcleo de Telessaúde da Universidade Federal do Rio Grande do Sul, financiado pelo Ministério da Saúde através do Programa de Apoio ao Desenvolvimento Institucional do Sistema Único de Saúde, contando com uma central de comando na sede da Universidade e oito salas de exame remoto distribuída pelo Estado do Rio Grande do Sul; Zanotto et al (2019, p. 1353-1355) verificaram que apesar do valor unitário considerado tenha sido de R $\$ 119$, oo por diagnóstico, houve acentuada queda do custo real unitário ao longo do período avaliado, considerando a realização de 1080 laudos/mês houve redução de $\mathrm{R} \$ 783,00$ para $\mathrm{R} \$ 283,00$, caracterizando-se como fator de redução do custo-benefício a curva de aprendizagem do implemento tecnológico. Constatou-se que a maturidade a ser adquirida durante o período de aprendizado do serviço "contribui para o melhor alinhamento de disponibilidade de profissionais por 
atividade, tornando o serviço mais equilibrado", apesar de ainda permanecer em valor acima dos custos de implantação.

Nesse sentido, Wen (2011, p. 99) assevera que qualquer ação em telemedicina demanda adequação, treinamento de equipe e recursos humanos, além de estratégia logística de acesso aos serviços, sua "aplicação e efetiva implantação devem acontecer com uma avaliação criteriosa dos diversos fatores que podem agregar valor a uma determinada atividade", sincronizando-se a utilização com os benefícios que traz de modo a se sustentar a partir do aspecto econômico-financeiro.

Tais inconclusividades demonstram a necessidade de que mais projetos experimentados passem a considerar o viés abordado nesta subseção; mesmo assim, algumas constatações podem ser extraídas, e a primeira é a possibilidade de considerar práticas similares ao primeiro projeto, desde que compreendida a mesma conduta de implementação, em serviços de custeio honorífico médico de baixo valor via SUS, como exemplo consulta médica de atenção especializada ( $R \$ 10,00)$, consulta médica em saúde do trabalhador ( $R \$ 10,00)$, consulta/atendimento domiciliar na atenção especializada ( $\mathrm{R} \$ 3,14)$, análise de caracteres físicos, elementos e sedimentos da urina ( $\mathrm{R} \$$ $3,70$ ), atendimento de pronto atendimento médico ( $\mathrm{R} \$ 11,00)$, atividade educativa/orientação em grupo na atenção especializada ( $\mathrm{R}$ \$ 2,70) (MINISTÉRIO DA SAÚDE, 2019).

No entanto, ao considerar o segundo caso, verifica-se a necessidade de maior estudo quanto às possibilidades de implementação da telemedicina noutras modalidades, inúmeros são os procedimentos médicos e correspondentes procedimentos, variados também são os recursos tecnológicos, comportando a telemedicina desde tele-orientação, teleconsulta até a realização de exames e procedimentos cirúrgicos remotos, ressalvando-se que o prévio preparo de equipes pode atuar como fator preponderante à viabilidade econômica de projetos.

Em contrapartida, o fator benefício não pode apenas alcançar as compensações econômicas, como já salientado. As benesses à saúde 
são influenciadoras do âmbito econômico, e sob o ponto de vista jurídico, há de ressaltar a efetiva realização igualitária, justa e universal desse direito como reconhecimento de tutela primordial de cidadania, alcançando concretização de direitos fundamentais.

\subsection{A telemedicina como fator de equilíbrio demográfico}

A Constituição Federal de 1988 destacou a importância de olhar regionalizado "seja por seus dispositivos especificamente de interesse regional, seja pela instituição definitiva do Federalismo Cooperativo como forma de federalismo brasileiro" (BERCOVICI, 2005, p. 87 e 89), tendo por fim elementar introduzir sob a ótica da Teoria do Estado o seu funcionamento em dupla função, de induzir e planejar o modelo desenvolvimentista pretendido à sociedade (LIMA; NOGUEIRA, 2019, p. 13).

O processo de desenvolvimento econômico no Brasil acabou por transformar determinadas regiões em polos de desenvolvimento e outras regiões estagnadas ou em situação de subdesenvolvimento. Tais inferências não devem ser consideradas como determinantes no processo desejado, o subdesenvolvimento nada mais é do que "um processo histórico autônomo, e não uma etapa pela qual tenham, necessariamente, passado as economias que já alcançaram grau superior de desenvolvimento" (FURTADO, 1968, p. 197).

Acrescenta-se o reforço teórico de Gilberto Bercovici em defesa do sistema colaborativo entre entes federados e o Poder central, substituindo-se a mera distribuição de verbas pela busca de condições efetivas de produção de riquezas objetivando "a igualação das condições sociais de vida e a redução das desigualdades socioeconômicas em todo o território nacional" (BERCOVICI, 2005, p. 91). 
Dados divulgados pelo Instituto Brasileiro de Geografia e Estatística - IBGE, estima-se em 2019 população brasileira de 210,1 milhões de pessoas. Denota-se concentração demográfica heterogênea no território nacional, sendo a região Sudeste a mais sobrecarregada, com 88,3 milhões - o Estado de São Paulo comportando 22\% do montante nacional - acompanhada por Nordeste (57 milhões), Sul (29,9 milhões), Norte (18,4 milhões) e Centro-Oeste (16,2 milhões) (IBGE, 2019).

Objetivando traçar o perfil sociodemográfico dos médicos recém-formados, Scheffer et al. (2018, p. 17-24) constataram a preferência dos profissionais por lotação em centros mais desenvolvidos, tais como no Estado de São Paulo (26,9\% dos inscritos), Minas Gerais (10,5\%), enquanto que locais como Acre, Mato Grosso, Rondônia, Roraima, Sergipe, Rio Grande do Norte e Alagoas margearam na casa de $1 \%$, ou menos.

A demografia médica brasileira é outro fator a ser considerado; pesquisa realizada junto ao Conselho Federal de Medicina demonstra a existência de 523.994 médicos com cadastros ativos; destes mais de 141 mil estão situados somente no Estado de São Paulo; regionalmente estão distribuídos da seguinte forma: Região Sudeste (270,3 mil), Nordeste (117,6 mil), Sul (75,8 mil), Centro-Oeste (38,8 mil) e Sul (21,3 mil) (CFM, 2020).

Cruzando-se os dados obtidos as disparidades vêm à tona: a média demográfica nacional calculada é de 1 médico para 401 pessoas. Verifica-se que nas regiões Sul e Sudeste se encontram os Estados com maior número de médicos, despontando-se entre os primeiros Rio de Janeiro (1/324), São Paulo (1/324), Rio Grande do Sul (1/351), Espirito Santo (1/388), Minas Gerais (1/390), Paraná (1/421) e Santa Catarina (1/437), merecendo destaque a capital federal com 1 médico para cada 419 pessoas. Na outra ponta, amargam piores índices as Regiões Norte e Nordeste, chamando atenção os Estados do Amapá (1/1.124), Maranhão (1/1.176), Pará (1/1.021), Acre (1/945), Amazonas (1/807), com médias muito acima do plano nacional. 
Sobre o ponto de vista da prestação de serviços domiciliares diretos, de acordo com Pesquisa Nacional por Amostra de Domicílios Contínua - PNAD contínua do quarto trimestre de 2018, verificou-se que 99,2\% das casas que dispunham de serviço de internet o celular era o equipamento utilizado para acesso (IBGE, 2018, p. 43). Houve crescimento na utilização da internet de 74,9\% dos domicílios do país em 2017 para 79,1 \% em 2018, com índice acelerado no tocante à população da zona rural (de 41\% em 2017 para 49,2\% em 2018) (IBGE, 2018, p. 36).

Alguns dados tornam o ambiente, se não ideal, ao menos favorável à implantação da telemedicina no Brasil; exemplo disso é a evolução dos acessos e densidade de telefonia móvel: no mês de fevereiro de 2005, computaram-se 67,4 milhões de acessos, saltando para 226,2 milhões em março de 2020. Ao comparar a densidade regional a cada 100 habitantes se percebe disparidades: a capital federal aparece na ponta com o índice de 117,63, seguida por São Paulo $(107,63)$, Rio de Janeiro (106), Goiás $(104,88)$, Mato Grosso $(103,67)$ e Mato Grosso do Sul (101,09); do lado oposto estão Pará $(80,06)$, Paraíba (79,27), Alagoas (76,09) e Maranhão (72,12). Apesar das diferenças que devem ser equacionadas, nota-se que mesmo nas regiões de menor densidade ainda assim são mensuradas altas acessibilidades, o que permite afirmar a possibilidade de oferta aos serviços telemáticos a grande faixa de brasileiros (ANATEL, 2020).

A telemedicina, pela dinâmica empregada, coloca-se como instrumento de equilíbrio à distribuição dos serviços médicos, possibilitando que tais fatores demográficos sejam amenizados uma vez que em sendo implementado possibilitará que médicos e pacientes se relacionem independentemente do local em que estiverem situados, agindo como janela bivalente, seja para que as pessoas possam ter em disponibilidade uma gama maior de profissionais e especialidades médicas, seja para que profissionais e empresas possam oferecer serviços a número maior de pessoas, alcançando locais onde a escassez de profissionais faz parte da realidade da população. 


\section{CONCLUSÃo}

Verifica-se que a Ordem Econômica e a Social possuem estreita correspondência entre si à prevalência do Bem-Estar assegurado na Constituição Federal. Com destaque ao direito à saúde, a telemedicina se comporta como objeto estimulador das duas dimensões constitucionais uma vez estar dotada de inúmeros atributos, dentre eles, agente de aperfeiçoamento profissional e institucional, potencializador do acesso universal e integral à saúde; por seu caráter inovador, coloca-se como meio alternativo de empreendimento e crescimento econômico, tais fatores, em conjunto, funcionam como redutores de desigualdades e incentivo ao desenvolvimento.

Denota-se, também, que políticas públicas em saúde não apenas confirmam a preponderância das garantias constitucionais, mas efetivam inúmeras conjunturas de direitos cuja dorsal é sustentada pela dignidade da pessoa humana, colocando-se a tecnologia como aliada à satisfação de tais direitos e, no caso da telemedicina, grande ferramenta de propulsão a esse propósito.

Há de considerar que o ambiente pandêmico influenciou diversos setores anunciando, se não uma nova crise, a instalação de quadro crítico de dimensões econômicas e sociais distintos, ensejando reflexões disruptivas com olhar de enfrentamento e superação do impasse, exsurgindo a telemedicina como instrumento corroborante do direito à saúde, dotado de valor econômico, influenciando beneficamente ambas as dimensões constitucionais de sustentação da Ordem.

Ao fito da redução de desigualdades, a telemedicina possibilita desobstaculizar algumas disparidades características do território brasileiro, levando aos mais recônditos cantos os mesmos serviços praticados em grandes centros especializados. Apesar de alguns 
experimentos positivos no campo da pesquisa e práticas privadas, a telemedicina necessita ser definitivamente implementada não apenas nas especialidades provisoriamente definidas, equalizando-se às melhores práticas internacionais de saúde e com isso, possibilitar o gozo de todo potencial que guarda em si.

Levando-se em conta o aspecto demográfico populacional e a distribuição de médicos pelo país, a telemedicina pode funcionar como fator de equilíbrio às disparidades evidenciadas, propiciando que a proporção de médicos/cidadãos seja equalizada, contribuindo com isso ao fundamento constitucional de acesso integral e universal à saúde. Não apenas se comporta como instrumento a ser difundido na seara pública, diante das peculiaridades da COVID-19, reveste-se de meio alternativo à iniciativa privada, com boas perspectivas de empreendedorismo.

$\mathrm{Na}$ relação custo-benefício dos projetos considerados, a incipiência empírica não confere constatações absolutas de benefícios no seio financiamento/valores praticados, possibilitando apenas inferências no sentido de eventuais vantagens para a prática da telemedicina em serviços de baixo custo conforme os valores honoríficos da tabela SUS, a citar as teleconsultas e avaliações de exames. Em contrapartida, constata-se que o treinamento adequado pode ser fator de melhoria da relação custo-benefício, necessitando maior reflexão no tocante a novas modalidades telemáticas que eventualmente demandem altos gastos por utilização de recursos tecnológicos mais sofisticados, apesar que em se considerando o viés jurídico, a concussão efetiva da norma constitucional ao direito à saúde compreende outros valores não calculados somente em quadro de custeio.

Conclui-se que a telemedicina se comporta como agente multifacetado na medida em que proporciona inúmeros benefícios que replicam importantes valores tanto de ordem social, quanto econômica; em conjunto são capazes de dar maior efetividade de tutelas fundamentais do ser humano e relevantes impulsos no 
crescimento econômico; em afluência, gatilhos de desenvolvimento humano e econômico, razão que a sua definitiva implementação se faz de rigor.

Data de Submissão: 01/06/2020

Data de Aprovação: 19/06/2020

Processo de Avaliação: double blind peer review

Editor Geral: Jailton Macena de Araújo

Editor de Área: Fernando Joaquim Ferreira Maia

Assistente Editorial: Maria Aurora Medeiros

\section{REFERÊNCIAS}

ACESSO à internet e à televisão e posse de telefone móvel celular para uso pessoa PNAD CONTÍNUA 2018. BRASÍL: IBGE, 2018. Disponível em:

https://www.ibge.gov.br/estatisticas/sociais/educacao/17270-pnadcontinua.html?edicao=27138\&t=sobre. Acesso em: 25 mai. 2020.

ANDRADE, M. V.; MAIA, A. C.; CARDOSO, C. S.; ALKMIM, M. B.; RIBEIRO, A. L. P. Custo-benefício do serviço de telecardiologia no Estado de Minas Gerais: Projeto Minas Telecardio. Arq. Bras. Cardiol., São Paulo, v. 97, n. 4, p. 307-316, out. 2011. Disponível em: https://www.scielo.br/scielo.php?pid=Soo66782X2011001300006\&script $=$ sci arttext\&tlng $=$ pt. Acesso em: 28 abr. 2020.

BERCOVICI, G. Constituição econômica e desenvolvimento: uma leitura a partir da Constituição de 1988. São Paulo: Malheiros, 2005 . 
A Necessária Regulamentação Da Telemedicina No Brasil Na Perspectiva Do...

BÖHM, G. M. Telemedicina no Brasil. 2013. Disponível em: https://telemedicina.fm.usp.br/portal/telemedicina-no-brasil/. Acesso em: 20 mai. 2020.

BRASIL. [Constituição de 1988]. Constituição [da] República Federativa do Brasil. Brasília: Senado Federal, 1988.

BRASIL. Agência Nacional de Telecomunicações. Resolução no $\mathbf{5 3}$, de 14 de setembro de 1998. Instalação do Comitê sobre Infraestrutura Nacional de informações. Brasília, 15 set. 1998.

BRASIL. Congresso Nacional. Lei 13.979, de o6 de fevereiro de 2020. Dispõe sobre as medidas para enfrentamento da emergência de saúde pública [...]. Brasília, o7 fev. 2020.

BRASIL. Congresso Nacional. Lei 9.998, de 17 de agosto de 2000. Institui o Fundo de Universalização dos Serviços de Telecomunicações. Brasília, 18 ago. 2000.

BRASIL. Conselho Federal de Medicina. Ofício CFM no

1.756/2020 - COJUR, de 19 de março de 2020. Disponível em: http://portal.cfm.org.br/images/PDF/2020 oficio telemedicina.pdf . Acesso em: 26 abr. 2020.

BRASIL. Conselho Federal de Medicina. Resolução no 1.643, de 7 de agosto de 2002. Define e disciplina a prestação de serviços através da Telemedicina. Brasília, 26 ago. 2002.

BRASIL. Conselho Federal de Medicina. Resolução no 2.227, de 13 de dezembro de 2018. Define e disciplina a telemedicina como forma de prestação de serviços médicos mediados por tecnologias. Brasília, 6 fev. 2019.

BRASIL. Conselho Federal de Medicina. Resolução no 2.228, de 26 de fevereiro de 2019. Revoga a Resolução CFM no 2.227 [...] e restabelece expressamente a vigência da Resolução CFM n ${ }^{0}$ 1.643/2002. Brasília, 6 mar. 2019.

BRASIL. Conselho Federal de Medicina. Resolução no 2.264, de 12 de novembro de 2019. Define e disciplina a telepatologia como forma de prestação de serviços de anatomopatologia mediados por tecnologias. Brasília, 20 set. 2019.

BRASIL. Decreto no 10o, de 16 de abril de 1991. Institui a Fundação Nacional de Saúde e dá outras providências. Brasília, 17 abr. 1991.

BRASIL. Ministério da Saúde. Portaria no 1.229, de 14 de junho de 2012. Estabelece recursos financeiros destinados ao Programa Nacional Telessaúde Brasil Redes. Brasília, 14 jun. 2012. 
BRASIL. Ministério da Saúde. Portaria no 2.546, de 27 de outubro de 2011. Redefine e amplia o Programa Telessaúde Brasil, que passa a ser denominado Programa Nacional Telessaúde Brasil Redes (Telessaúde Brasil Redes). Brasília, 27 out. 2011.

BRASIL. Ministério da Saúde. Portaria no 467, de 20 de março de 2020. Dispõe, em caráter excepcional e temporário, sobre as ações de Telemedicina, [...] decorrente da epidemia de COVID-19. Brasília, 23 mar. 2020.

BRASIL. Ministério da Saúde. Portaria no 561, de 16 de março de 2006. Institui no âmbito do Ministério da Saúde a Comissão Permanente de Telessaúde. Brasília, 17 mai. 2006.

BRIGGS, A. The Welfare State in historical perspective. In: PIERSON, C.; CASTLES, F. G.; The Welfare State reader. $2^{\circ}$ ed. Cambridge: Polity Press, 2006.

CARDOSO, H. R.; FEITOSA, M. L. A. M. Direitos Sociais, Saúde Pública no Brasil, precarização dos vínculos funcionais e reflexos para o usuário do Sistema Único de Saúde - SUS.Prim@ Facie, João Pessoa, v. 13, n. 25, p. 1-47, 2014. Disponível em:

https://periodicos.ufpb.br/index.php/primafacie/article/view/26746 1425. Acesso em: 28 abr. 2020.

CASSIOLATO, J. E. As políticas de ciência, tecnologia e inovação na China. In: Boletim de Economia e Política Internacional. Governo Federal: repositório do conhecimento do Instituto de Pesquisa Econômica Aplicada (RCIpea). 2013. p. 65-80. Disponível em: http://repositorio.ipea.gov.br/bitstream/11058/3928/1/BEPI n13 politicas.pdf. Acesso em: 25 mai. 2020.

CECATO, M. A. B.; OLIVEIRA, A. A. de. Direitos Sociais: do Estado Liberal ao Estado Social. Prim@ Facie. João Pessoa, v. 15, n. 29, p. 1-25, 2016. Disponível em:

https://periodicos.ufpb.br/index.php/primafacie/article/view/33120 L17165. Acesso em: 16 jun. 2020.

CHINA - Índice de desenvolvimento humano.

COUNTRYECONOMY: 2018. Disponível em:

https://pt.countryeconomy.com/demografia/idh/china. Acesso em: 25 mai. 2020.

CIDADES e Estados. BRASIL: IBGE, 2019. Disponível em: https://www.ibge.gov.br/cidades-e-estados/. Acesso em: 25 maio 2020.

ESPING-ANDERSEN, G. As três economias políticas do welfare state: o legado da economia política clássica. Lua Nova: Revista de Cultura e Política, São Paulo, n. 24, p. 85-116, set. 1991. Disponível 
A Necessária Regulamentação Da Telemedicina No Brasil Na Perspectiva Do...

em: http://www.scielo.br/scielo.php?pid=SO102-

64451991000200006\&script=sci arttext. Acesso em: 28 abr. 2020.

ESTATÍSTICAS. BRASIL: CFM, 2020.

http://portal.cfm.org.br/index.php?option=com_estatistica. Acesso em: 25 maio 2020.

FEITOSA, M. L. P. de A. M.; SILVA, P. H. T. da. Indicadores de desenvolvimento humano e efetivação de direitos humanos: da acumulação de riquezas à redução da pobreza. Revista de Direitos e Garantias Fundamentais. Vitória, n. 11, p. 119-147, jan-jun. 2012. Disponível em:

http://sisbib.emnuvens.com.br/direitosegarantias/article/view/205. Acesso em: 16 jun. 2020.

FURTADO, C. Teoria e política do desenvolvimento

econômico. Belo Horizonte: Biblioteca Universitária, 1968.

HAGENAARS, A.; DE VOS, K. The definition and measurement of poverty. The Journal of Human Resources, v. 23, n. 2, p. 211221, Spring 1988.

KAGEYAMA, A.; HOFFMANN, R. Pobreza no Brasil: uma perspectiva multidimensional. Economia e Sociedade, Campinas, v. 15, n. 1, p. 79-112, jan-jun. 2006. Disponível em:

https://periodicos.sbu.unicamp.br/ojs/index.php/ecos/article/view/ 8642922/10492. Acesso em: 25 mai. 2020.

KHOURI, S. G. E. Telemedicina: análise da sua evolução no Brasil. 2003. Dissertação (Mestrado em Ciências) - Faculdade de Medicina, Universidade de São Paulo. São Paulo, 2003.

LIMA, M. M. B.; NOGUEIRA, M. A. P. A contribuição de Rui Barbosa para a construção do pensamento político-constitucional brasileiro.

Prim@ Facie. João Pessoa, v. 18, n. 37, p. 1-23, 2019. Disponível em:

https://periodicos.ufpb.br/index.php/primafacie/article/view/3899 2/22585. Acesso em: 16 jun. 2020.

MELLO, G. A. Quando os paradigmas mudam na saúde pública: o que muda na história? História, Ciências, Saúde - Manguinhos, Rio de Janeiro, v. 24, n. 2, p. 499-517, abr-jun. 2017. Disponível em: http://www.scielo.br/scielo.php?pid=So10459702017000200499\&script=sci arttext. Acesso em: 28 abr. 2020.

MIOTTO, B. A.; MAINARDI, G. M. Demografia médica no Brasil 2018. São Paulo: FMUSP, CFM, Cremesp, 2018. Disponível em: https://repositorio.usp.br/item/002889584. Acesso em: $28 \mathrm{abr}$. 2020. 
NADAI, M. O que foi o acidente com o césio-137 em Goiânia

(GO)?. 19 set. 2018. Disponível em:

https://super.abril.com.br/mundo-estranho/o-que-foi-o-acidentecom-0-cesio-137/. Acesso em: 28 abr. 2020.

PAIM, J. S. Direito à saúde, cidadania e Estado. In:

CONFERÊNCIA NACIONAL DE SAÚDE, 8., 1986, Brasilia, DF. [...].

Brasilia: Centro de Documentação do Ministério da Saúde, 1987. p.

45-59. Disponível em:

https://bvsms.saude.gov.br/bvs/publicacoes/0219VIIIcns.pdf.

Acesso em: 28 abr. 2020.

PNUD - Programa das Nações Unidas para o Desenvolvimento.

Relatório do Desenvolvimento Humano 2019. Além do rendimento, além das médias, além do presente: desigualdades no desenvolvimento humano no século XI. 2019. Disponível em: http://hdr.undp.org/sites/default/files/hdr 2019 pt.pdf. Acesso em: 15 mai. 2020.

RIBEIRO FILHO, J. L.; MESSINA, L. A.; SIMÕES, N.; COURY, W. Telemedicina e Telessaúde: a construção de redes colaborativas de ensino, pesquisa e assistência ao diagnóstico e ao tratamento em saúde no Brasil. Informática Pública, Rio de Janeiro, v. 10, n. 2, p. 97-104, 2008. Disponível em:

http://www.ip.pbh.gov.br/ANO10 N2 PDF/telemedicina telesaude dossie.pdf. Acesso em: 28 abr. 2020.

SABBATINI, R. História da informática em saúde no Brasil.

Informática Médica. Campinas: [edição online], v. 1, n. 5, set-out. 1998. Disponível em:

http://www.informaticamedica.org.br/informaticamedica/no105/sa bbatini.htm. Acesso em: 20 mai. 2020.

SABBATINI, R. M. E. A telemedicina no Brasil: evolução e perspectivas. 2012. Disponível em:

http://www.sabbatini.com/renato/papers/Telemedicina Brasil Evo lucao Perspectivas.pdf. Acesso em: 28 abr. 2020.

SANTOS, A. M. A. dos; JACINTO, P. de A.; TEJADA, C. A. O. Causalidade entre Renda e Saúde: Uma análise através da abordagem de dados em painel com os Estados do Brasil. Estudos

Econômicos, São Paulo, v. 42, n. 2, p. 229-261, abr-jun. 2012. Disponível em: http://www.revistas.usp.br/ee/article/view/36076. Acesso em: 25 mai. 2020.

SARLET, I. W.; FIGUEIREDO, M. F. Reserva do possível, mínimo existencial e direito à saúde: algumas aproximações. Revista de Doutrina da 4 ${ }^{\mathbf{a}}$ Região, n. 24, jul. 2008.

SCHEFFER, M. (Coord.); CASSENOTE, A.; GUILLOUX, A. G. A.; BIANCARELLI; A.; 
A Necessária Regulamentação Da Telemedicina No Brasil Na Perspectiva Do...

SCHUMPETER, J. A. Teoria do desenvolvimento econômico: uma investigação sobre lucros, capital, crédito, juro e o ciclo econômico. Traduzido por Maria Sílvia Possas. São Paulo: Nova Cultural Ltda, 1997.

SILVA, A. B.; CARNEIRO, A. C. M. G.; SINDICO, S. R. F. Regras do governo brasileiro sobre serviços de telessaúde: revisão integrativa. Planejamento e políticas públicas, Brasília, n. 44, p. 167-188, 2015. Disponível em:

http://www.ipea.gov.br/ppp/index.php/PPP/article/view/440. Acesso em: 28 abr. 2020.

SIMÕES, N.; COURY, W.; RIBEIRO, J. L.; ARAÚJO, G.; CAETANO, D.; MESSINA; L. A. A Rede Universitária de Telemedicina - RUTE. In: MESSINA, L. A.; RIBEIRO FILHO, J. L (ed.). Impactos da Rede Universitária de Telemedicina: Ações de educação contínua, pesquisa colaborativa, assistência, gestão e avaliação remota. Fase I. 2006/2009. Rio de Janeiro: E-papers, 2013.

TABELA SUS referência setembro 2019. BRASIL: Ministério da Saúde, 2019. Disponível em:

https://www.cisamusep.org.br/uploads/credenciamento/86 Tabela SUS referencia-SETEMBRO 2019.pdf. Acesso em: 25 mai. 2020.

TELEFONIA Móvel. BRASIL: ANATEL, 1 mar. 2020. Disponível em: https://www.anatel.gov.br/paineis/acessos/telefonia-movel. Acesso em: 25 mai. 2020.

UGALMUGLE, S.; SWAIN, R. Global telemedicine Market size to surpass \$175 Bn by 2026. 13 abr. 2020. Disponível em: https://www.gminsights.com/pressrelease/telemedicine-market. Acesso em 25 mai. 2020.

WEN, C. L. Telemedicina e telessaúde: aplicação de tecnologia para promover educação interativa e formação de rede de interconsulta profissional em saúde. In: TRINDADE, M. A. B. (org.). As tecnologias da informação e comunicação (TIC) no desenvolvimento de profissionais do Sistema Único de Saúde (SUS). São Paulo: Instituto da saúde; 2011. P. 95-112.

ZANOTTO, B. S.; ETGES, A. P. B. da S.; SIQUEIRA, A. C.; SILVA, R. S. da.; BASTOS, C.; ARAUJO, A. L. de; MOREIRA, T. de C.;

MATTURRO, L.; POLANCZYK, C. A.; GONÇALCES, M. Avaliação Econômica de um serviço de telemedicina para ampliação da atenção primária à saúde no Rio Grande do Sul: o microcusteio do Projeto TeleOftalmo. Ciência \& Saúde Coletiva. Rio de Janeiro, v. 25, n. 4, p. 1349-1360, abr. 2020. Disponível em: https://www.scielosp.org/article/csc/2020.v25n4/1349-1360/. Acesso em: 28 abr. 2020. 


\title{
The Necessary Regulation Of Telemedicine In Brazil From The Development Perspective: The Covid-19 Crisis As A Parameter To Be Observed
}

\author{
Jefferson Patrik Germinari
}

\section{Marisa Rossignoli}

\author{
Bruno Bastos de Oliveira
}

\begin{abstract}
The pandemic caused by COVID-19 resumed the discussions around telemedicine, whose previously unregulated modalities started to be provisionally authorized to face the crisis. This article aims to analyze this scenario under constitutional prerogatives, focusing on the right to health and the State's role in human and economic development. Deductive research methodology was adopted, based on the general idea circulating in constitutional norms inclined to social and economic rights. It is concluded, considering the pandemic crisis of COVID-19 as a rupturing moment, that the definitive regulation of telemedicine in Brazil can provide a favorable environment for the implementation of social and economic values, giving greater effectiveness to the fundamental guardianships of the human being, thus assuming the role of trigger for expanding human and economic development.
\end{abstract}

Keywords: Regulation. Telemedicine. COVID-19. Development. 